\title{
Chief Digital Officers' Evolving Strategies: Balancing Lightweight and Heavyweight IT During the Digital Transformation
}

\author{
Kjersti Berg Danilova \\ NHH Norwegian School of \\ Economics \\ kjersti.danilova@,nhh.no
}

\author{
Jon Iden \\ NHH Norwegian School of \\ Economics \\ jon.iden@nhh.no
}

\author{
Bendik Bygstad \\ University of Oslo \\ bendikby@ifi.uio.no
}

\begin{abstract}
In this paper, we investigate how chief digital officers (CDOs) deal with the digital transformation over time. The study is based on interviews with the CDOs of 26 Norwegian organizations, conducted over a three-year period. Our analytical lens involves differentiating between the knowledge regimes of heavyweight and lightweight IT. Based on the CDOs' perceptions, we identify three important shifts related to strategic, technological, and methodological aspects, all indicating a more balanced approach to the interplay of heavyweight and lightweight IT. We contribute to the literature on the digital transformation and CDOs' contribution, and to the theory of lightweight vs. heavyweight IT.
\end{abstract}

\section{Introduction}

Over the past few years, organizations aiming to speed up the digital transformation increasingly have established chief digital officers (CDOs) as a new position within their organizations $[1,2]$. Frequently, the establishment of CDOs reflects a perception of current IT managers (such as chief information officers [CIOs]) as representative of traditional IT [3], indicates a potential divergence between business and IT interests [4], and sometimes echoes a history in which mutual understanding, support, and relations between the IT department and business units have seemed inadequate [5]. CDOs often are viewed as closer to the business and its customers, and as evangelists of innovation using novel lightweight technologies [6]. Studies on the CDO's contribution to the digital transformation largely have focused on different role types that the CDO might adopt, such as digital advocates, entrepreneurs, and digital accelerators [3, 6]. What we know less about is how central issues for CDOs evolve over time, and how CDOs respond to these changes. The background for this investigation is that the CDO's role is new, and many CDOs had to define much of the role themselves and establish a position [3]. Moreover, this has been taking place during a period of rapid business change and technological innovation amid international discourse on the digital transformation [7]. In this study, we present the results from a longitudinal study of CDOs, focusing on their changing perceptions of key priorities and how these perceptions guide their actions. Our research question is: How are CDOs' strategies evolving during the digital transformation?

We framed our investigation using the notions of heavyweight and lightweight IT, which Bygstad [8] described as two different knowledge regimes. Heavyweight IT denotes traditional IT department solutions and methods, while lightweight IT concerns mobile and Internet of Things (IoT) technologies, and fast innovation. We chose this perspective because the CDOs relate to a broad number of issues tied to the digital transformation beyond technology. The lightweight/heavyweight IT framework focuses on strategic, technological, and methodological issues. Furthermore, studies on the digital transformation tend to focus on novel "light" technologies [9], but recent studies suggest that both lightweight and heavyweight IT together play a vital role in successful digital change $[10,11]$.

As our empirical approach, we conducted interviews with CDOs from 26 organizations altogether, during two separate time periods. By examining the digital transformation through CDOs' eyes, we detected three important shifts over time in how CDOs approach the digital transformation.

This study contributes to research on the digital transformation and chief digital officers. We also contribute to the theory of lightweight vs. heavyweight IT. Our findings are valuable for organizations that seek to accomplish their own digital transformations.

\section{Background}

\subsection{Digital transformation}

This study's contextual background is the digital transformation, a process in which 
organizations set out to transform their businesses by combining and utilizing digital technology and data. External factors are driving the digital transformation, such as intensified competition, and/or opportunities emerging from new technologies, such as digital platforms, apps, big data, analytics, artificial intelligence (AI), IoT, and robotics [12]. Some researchers postulate that the term digital transformation signifies a radical transformation of business models and organizational structures to create a new value proposition and organizational identity [7]. The present study follows an understanding of the digital transformation as a process of fundamental strategic change accomplished incrementally, over time, that does not necessarily entail altering the entire business model: "Digital transformation is an ongoing process of strategic renewal that uses advances in digital technologies to build capabilities that refresh or replace an organization's business model, collaborative approach, and culture" [13]. Also in this perspective, the digital transformation requires extensive organizational change that affects the routines, knowledge, and capabilities of members at all levels. New skill sets are required to adopt, master, and manage new digital technologies, as well as integrate the technologies into processes, services, and products [14]. The transformation is not the result of a single digitalization project, but rather of a combination of various digital and organizational changes implemented over time [15]. During this process, leaders must handle both strategic and organizational issues, as well as make important decisions on which technologies to emphasize and which methods to employ, and on who should lead the transformation and own the changes.

\subsection{Chief digital officer}

To drive the digital transformation, organizations appoint CDOs and establish units to initiate, coordinate, and oversee activities $[2,3]$. The expected benefits from a CDO are determined by organizations' sense of transformation urgency based on their current business models and competitive environments, and on their need for better coordination of transformation activities [2]. Recent studies have found that the appointment of a CDO positively impacts firm value as perceived by investors [16] and the stock market [17, 18].

Research on CDOs has helped build typologies of different roles that CDOs might play and combine $[3,6,19]$. Other studies have examined the factors needed for CDOs to succeed, including specialized skills $[19,20]$, and the design of organizational structures and mandates [1, 19, 21]. Less is known about how CDOs accomplish digital transformation, particularly as the transformation progresses over time. One of the few studies that has examined in- depth how CDOs enact their role is a study by Tumbas et al. [22]. Through an institutional logics perspective, they described how CDOs define a digital logic that differs from existing IT logic, and how they seek to enact this logic through different strategies that aim to manage tensions between the logics. They found that CDOs manage the tensions partly through strategies involving integration (grafting, bridging) and partly through decoupling the logics. Tumbas et al.'s study provides a valuable contribution to research on CDOs, with conclusions pertinent to the context of digital innovation, but it does not take a longitudinal perspective on the CDO's function in the digital transformation.

\subsection{Analytical lens: Lightweight and heavyweight IT}

Bygstad's [8] terms "lightweight" and "heavyweight" refer not only to "light" and "heavy" technologies, but also to knowledge regimes, as illustrated in Table 1. Heavyweight IT is driven by IT professionals, enabled by systematic specifications and proven digital technology, and realized through software engineering. However, lightweight IT is a knowledge regime driven by competent users' need for solutions, enabled by the consumerization of digital technology, and realized through innovation processes.

Table 1. Heavyweight and lightweight IT

\begin{tabular}{|l|l|l|}
\hline & Lightweight IT & Heavyweight IT \\
\hline Strategy & $\begin{array}{l}\text { Fast business } \\
\text { innovation, driven } \\
\text { by windows of } \\
\text { opportunity }\end{array}$ & $\begin{array}{l}\text { Incremental } \\
\text { development, based } \\
\text { on company needs }\end{array}$ \\
\hline Technology & $\begin{array}{l}\text { Front-end: Process } \\
\text { support; apps; BI; } \\
\text { social media }\end{array}$ & $\begin{array}{l}\text { Back-end: } \\
\text { transaction systems; } \\
\text { enterprise solutions }\end{array}$ \\
\hline Methods & $\begin{array}{l}\text { Innovation, } \\
\text { experimentation }\end{array}$ & $\begin{array}{l}\text { Systematics, quality, } \\
\text { security }\end{array}$ \\
\hline
\end{tabular}

The two knowledge regimes can be described as different and opposing in terms of strategic, technological, and methodological factors. Strategic factors involve the profile and ownership of IT development and implementation. Bygstad [8] describes lightweight IT as front-end and businessoriented, and frequently owned and driven by users and vendors. Heavyweight IT takes a back-end perspective and traditionally remains the IT department's responsibility. Technologically, lightweight IT refers to digital technologies emerging during the past decade - such as mobile apps, robotics process automation, and the IoT - that are not necessarily fully integrated with other components of the IT architecture. Examples of 
heavyweight IT include PCs, servers, and legacy systems in an integrated network. Lightweight IT aims for flexibility, while heavyweight IT emphasizes stability [23]. Methodologically, lightweight IT accordingly entails a "light," experimental approach focusing on innovation, whereas heavyweight IT employs traditional, systematic methods in which security and quality are key objectives [8].

The lightweight and heavyweight knowledge regimes mirror elements of the digital logic vs. IT logic dichotomy described by Tumbas et al. [22] Likewise, their conclusions partly correspond. Bygstad [8] argued that because generativity varies in lightweight and heavyweight IT, in digital innovation, they should not be integrated, as innovation is best served by loose interaction between these with respect to technology, standards, and organization. However, digital transformation encompasses not only innovation, but also enhancing existing products or processes by means of existing digital technologies [24, 25]. Moreover, a digital transformation is not a quick fix, but a long haul that stretches over years and entails a focus on the whole enterprise architecture [26], and a "dynamic synchronization between business and IT" [27]. Based on this, we postulate that a digital transformation demands a balance between and tighter integration of lightweight and heavyweight IT.

\section{Research method}

How CDOs accomplish digital transformation over time has been an underexplored topic in academic research. Therefore, to address our research question, we decided to conduct an exploratory study in which we sought insight into the digital transformation and the CDO's role in a variety of organizations. We wanted to learn how the CDOs themselves understand the digital transformation, their role and strategies, as well as the challenges they face. Thus, we interviewed 20 CDOs in 2016-2017. Digital transformation was then a new phenomenon attracting increasing interest in research, media, and organizations, and organizations included in the study were in the early stages of digital transformation. We wanted to form a broader picture of the digital transformation and how CDOs' perceptions and strategies might change over time. Therefore, we followed up with a new round of interviews three years later (2019-2020) when we expected organizations to have progressed noticeably in their digital transformation.

\subsection{Data collection}

We focused on organizations based in Norway, either purely Norwegian organizations or Norwegian branches of multinational corporations.
Norway is viewed as one of the most digital countries in Europe based on the country's fixed and mobile broadband coverage, percentage of Internet users, integration of digital technology, and digitalization of public services [28]. The Norwegian economy remains strong, supported by large petroleum resources, with low unemployment and poverty rates. Simultaneously, economic growth has slowed over the past few years. Private organizations are experiencing increasing competition due to globalization and disruptive technologies, while the public sector is facing considerable challenges related to an aging population in the coming decades. The generally high cost of employment and shrinking natural resources are increasing the need for greater efficiency, further technological development, and innovation [29]. This backdrop makes Norwegian organizations particularly relevant to this study.

We identified potential informants through LinkedIn searches and invited 35 CDOs to participate in the first round of interviews, of which 20 accepted. By the time of the second round, some had left their organizations, and others declined the invitation. In the end, eight original participants partook in the second round. To strengthen the study, we decided to invite additional CDOs based on an expectation that the longitudinal perspective could be maintained through retrospective interviews. Six CDOs from organizations that had been in the process of digital transformation for some time joined the study. Thus, we conducted 34 interviews altogether (20 in 2016-17; 14 in 201920).

Table 2. CDOs Interviewed

\begin{tabular}{|l|l|l|l|}
\hline $\begin{array}{l}\text { CDO- } \\
\text { ID }\end{array}$ & Industry & Sector & Round \\
\hline CDO-1 & Insurance & Private & $1 \& 2$ \\
\hline CDO-2 & University & Public & $1 \& 2$ \\
\hline CDO-3 & Banking & Private & $1 \& 2$ \\
\hline CDO-4 & Media & Private & 1 \\
\hline CDO-5 & Directorate & Public & 1 \\
\hline CDO-6 & Service & Private & 1 \\
\hline CDO-7 & Municipality & Public & 1 \\
\hline CDO-8 & Municipality & Public & $1 \& 2$ \\
\hline CDO-9 & Banking & Private & $1 \& 2$ \\
\hline CDO-10 & Technical service & Private & $1 \& 2$ \\
\hline CDO-11 & Consultancy & Private & 1 \\
\hline CDO-12 & Technology & Private & 1 \\
\hline CDO-13 & Hotel & Private & 1 \\
\hline CDO-14 & Finance & Private & 1 \\
\hline CDO-15 & Transportation & Public & 1 \\
\hline CDO-16 & Security & Private & 1 \\
\hline CDO-17 & Information technology & Private & 1 \\
\hline CDO-18 & Banking & Private & 1 \\
\hline CDO-19 & Insurance & Private & $1 \& 2$ \\
\hline CDO-20 & Manufacturing & Private & $1 \& 2$ \\
\hline CDO-21 & Electronics retail & Private & 2 \\
\hline CDO-22 & Marine biotechnology & Private & 2 \\
\hline CDO-23 & Insurance & Private & 2 \\
\hline CDO-24 & Welfare services & Public & 2 \\
\hline CDO-25 & Maritime Industry & Private & $\mathbf{P}$ \\
\hline CDO-26 & Municipality & Public & 2 \\
\hline & & & \\
\hline
\end{tabular}


In both rounds, we sought to include organizations that represented a variety of entities in size and sector. Seven informants represented public organizations (universities, municipalities, welfare, directorate, transportation), and 19 represented private organizations from industries such as insurance, banking and finance, media, security, service, retail, and manufacturing. The organizations' size (as measured by number of employees) varied from about 100 employees to more than 15,000 . Several of the informants have technical education, while others have business education or specialized training related to their fields. Generally, the CDOs had extensive experience before they started in the position, typically including leadership and/or project manager roles. Most lead and are supported by a unit, though the unit's size varied from a couple of employees to hundreds. Two-thirds of the informants are part of top management teams.

We conducted in-depth, semi-structured interviews lasting up to one hour each. We asked the informants to tell us about their organization's digital strategy, purposes, methods, and challenges, as well as digitalization projects that the organization had undertaken so far or was planning to undertake. We asked questions about ownership of the digital transformation, technologies employed, and methodological issues. The second round of interviews addressed the same topics, but we also asked the CDOs specific questions about whether and how their perceptions and strategies had changed during the previous three years.

\subsection{Data preparation and analysis}

We recorded the interviews, with the informants' approval, and transcribed most of the interviews verbatim. For the interviews that were not transcribed, the interviewer wrote detailed summaries shortly after each of these interviews.

The data analysis started with two of the study authors reading through all the transcribed interviews and summaries several times, and coding the interviews independently, followed by in vivo coding, in which we highlighted words and sentences to identify key themes and issues. In a second round of coding, we relied on literature on heavyweight and lightweight IT [8], and used strategic, technological, and methodological aspects as categories in a coding scheme that included codes such as digital war/digital opportunities, focus, ownership, lightweight/heavyweight technology, and experimentation/systematic methods, as reflected in the shifts illustrated in Table 3 . Based on the coding, we developed a data matrix that we used to structure the findings in accordance with the two rounds of interviews to discern shifts over time.

\section{Findings}

Our data analysis reveals three major shifts as to how the CDOs approached the digital transformation within their organizations. First, the strategic shift illuminates how the CDOs changed their tactics and communicated to the organization the need for digital transformation and how to proceed. Second, the technological shift conveys how CDOs' technological focus and priorities changed during the effort. Third, the methodological shift illustrates how the CDOs altered how the digital initiatives were managed.

Table 3. Three shifts in CDOs' approaches to the digital transformation

\begin{tabular}{|l|l|l|}
\hline $\begin{array}{l}\text { Strategic } \\
\text { shift }\end{array}$ & $\begin{array}{l}\text { From } \\
\text { Owgital war } \\
\text { Owned by the CDO } \\
\text { Downsizing }\end{array}$ & $\begin{array}{l}\text { Digital opportunities } \\
\text { Owned by the organization } \\
\text { (business units + IT) } \\
\text { Strengthening the organization }\end{array}$ \\
\hline $\begin{array}{l}\text { Techno- } \\
\text { logical } \\
\text { shift }\end{array}$ & $\begin{array}{l}\text { Lightweight IT } \\
\text { In-house solutions } \\
\text { Process innovation }\end{array}$ & $\begin{array}{l}\text { Enterprise infrastructure } \\
\text { Digital ecosystems } \\
\text { Process architecture }\end{array}$ \\
\hline $\begin{array}{l}\text { Methodo- } \\
\text { logical } \\
\text { shift }\end{array}$ & $\begin{array}{l}\text { Fail-fast } \\
\text { experimentation } \\
\text { Radical change } \\
\text { Impressing customers } \\
\text { through quick wins } \\
\text { Projects }\end{array}$ & $\begin{array}{l}\text { Systematic methods } \\
\text { End-to-end customer journey }\end{array}$ \\
\hline \multicolumn{2}{|l}{}
\end{tabular}

\subsection{Strategic shift}

During the first round of interviews, the CDOs described the situation as chaotic and perilous, and talked at length about volatile business environments with increasing customer expectations and threats of disruption. The informants referred to technology and digitalization as a threat, or even a war, characterized by "destructive forces," "crisis," and "a dagger against the throat." A common perspective was that it was mandatory to react and do the right thing - if not, "someone else will" (CDO-6). Norwegian media supported this war discourse, in which disruption and digital transformation were fast becoming buzzwords. CDOs explained that executives jumped on the bandwagon mostly because of the sense of a war situation and the hype that media created, but with a limited understanding of digital technologies and transformation. CDO-3 complained: "We even had some statements at a board meeting, like, 'Aren't we soon done with the Internet now that we've got webpages up and running?,",

In this atmosphere, the CDOs were brought in as war generals to propel their organizations' digital transformation. Thus, the CDOs quickly assumed ownership, with some adopting a top-down approach: "We are dealing with some business areas that are generally used to making all the decisions 
themselves, and then we come and say, no, in this area - which they perceive as theirs - they cannot make the decision. That generates some discussions," CDO-1 commented. Others allowed for local autonomy, but took on an overall role as "legislator, resource controller, and strategist" (CDO-8). In particular, the CDOs took their roles as war generals seriously, and motivated executives and employees to take action by employing the war metaphor actively in their discourse: "Sometimes I have to kind of say that this will be bad, to move those who are more skeptical in the right direction, for budgets, focus, and resources not to suffer," CDO-20 explained. CDO-3 described the situation within the bank sector: "About half a year ago, I discovered PSD2 [Revised Payment Service Directive] while perusing some blogs, and I read through the whole directive and went straight to my boss and said, 'Everybody should put on a red Tshirt saying PSD2 because this is a crisis.",

The CDOs quickly realized that winning a digital war required getting both executives and the organization on board, and that updating executives on digital threats and strategic opportunities constitutes an important responsibility. Informants described spending a substantial amount of their time trying to make sense of the battlefield and conveying this to their organization. CDOs told about actively using social media and participating in industry seminars for this purpose: "I read lots of blogs. I use social media a lot. Twitter is great for updating myself. I participate in seminars around the world. Being updated on technology is one of the factors I am measured on. I am supposed to keep our executive group updated, and then I also need to be as well" (CDO-4).

At this time, downsizing was high on the agenda in the organizations, and some executives publicly announced hefty ambitions for downsizing and cutting costs by means of digital technology. Others chose to keep their cards closer to their chest, as CDO-1 exemplifies: "I think there is an idea that we're automatizing tasks for the employees to be less busy. But that is not why we digitalize; it is to make 20 percent of us redundant. There are some rather cynical calculations that few people see."

During the second round of interviews, we found that the sense of the purpose, objectives, and ownership of the digital transformation had shifted. Informants talked in retrospect about the preceding period, and a gradual realization that the threat of disruption and millennials' expectations might have been exaggerated, as CDO-1 explained: "Well, I think that all that fuss about threats in the beginning (...), I think all that about digitalization at any cost and just getting it out there, and that digitalization is the salvation, it has been toned down. "Informants indicated that this shift was a result of adopting a realistic perspective of the organization's strengths and weaknesses vs. those of competitors. Whereas industries such as finance and retail had lived in fear of black swan innovations and new entrants, they now started realizing the value of local market insight, possessing customers' trust, and establishing direct relations with customers. This realization fostered a new direction and a stronger focus on the opportunities offered by digital tools to provide value for users and customers, rather than on facing the threats through downsizing and costcutting. Even organizations that a few years back had publicized sizable downsizing goals gradually matured toward new objectives. CDO-9 elaborated: "We are now clear that we will not go through large rounds of downsizing by firing people and giving severance packages and the like. We would rather re-educate our employees toward the future ways of work. Our data science initiative is an example of this - 30 employees with completely different responsibilities were offered training in data science, and now they work as data scientists instead. (...) We have seen that it is harder to accomplish a transformation in a good way than we initially thought. We have learned a lot. We also have seen that it is about culture, people, leadership. A clear purpose of what we do - to be a positive force for customers, society, the environment, not just emphasizing short-term stockholder value. (...) We've been through an exciting journey from sort of 'Let us automate all our processes and reduce staff by five thousand', to a whole other focus today, which relates to purpose, culture, accountability, social responsibility, etc."

One of the informants commented that their own approach initially had been too much like that of an external consultant - "going into the organization and conducting an analysis, while the anchoring toward the business areas was often too weak" (CDO-1). Now, rather than pursuing a role as a war general, the CDOs recognized that succeeding with digital transformation required building necessary knowledge and competence in the organization to enable it to take ownership of the changes. Informants described efforts to increase digital competence at different levels through competence programs for leaders and employees, and by seeking specific skills when recruiting. Building an organization that can deal with digital challenges and building capacity for change became an important strategy for the CDOs. Accordingly, the CDOs witnessed a substantial rise in their organizations' understanding of what digitalization and digital transformation entail. This rise enabled CDOs to change their strategy regarding ownership of the digital transformation:

"The goal is not for me to remain the driving force, but for the whole organization to become digital. The fact is that the digital transformation of this organization should not be accomplished by my unit. 
For us to sit in a unit in a corner and try to do some digital stuff is not much use, right? It is our regular business which needs to change its mindset and work more digitally. So, I fail unless the other departments become digitally oriented. At some point, I hope I have succeeded so well in this regard that I won't be needed much longer" (CDO-4).

CDOs also emphasized facilitating collaboration between business units and the IT department, increasing mutual understanding, and "creating the feeling that we 're in on this together" (CDO-8). Leaving it to the organization to explore the potential with digital technologies soon bore fruit. The CDOs told how organizational units started searching for opportunities to improve processes through digitalization. This shift also resulted in a more long-term perspective on digital transformation, rather than the previous tendency of jumping on the first trend. This impacted the projects' scope, as well as the CDO's role. Instead of taking the driver's seat, the CDOs now viewed themselves as a support for the organization: "You must assume a 10- to 20-year perspective and build an organization that can drive continuous improvement itself. And in that, they need someone who can hold their hand in the process over time" (CDO-22).

\subsection{Technological shift}

During the first round of interviews, the CDOs' enthusiasm for novel lightweight technologies was prominent. When asked about ongoing digitalization projects and plans, hardly any of the informants talked about enhancing and exploiting the existing system portfolio, nor about large new ERP projects. Instead, informants talked enthusiastically about mobile apps, sensors, IoT, algorithms, robotic process automation, big data, AI, 3D printing, and digital platforms. As CDO-19 explained: "You need to kind of go along with the hype and know about the innovations which are coming and the possibilities which are out there." At this stage, solving customer problems through quick wins took center stage:

"Our definition of digitalization is restricted to changes that relate directly to the customer, such as self-service solutions. We look more at customer problems than actual processes. We don't develop anything unless it's something customers can notice. If there is a project involving only internal processes, that's not part of what we do" (CDO-1).

The CDOs emphasized digitalizing individual business processes and designing front-end solutions without necessarily examining related processes and taking an end-to-end perspective: "What's important is to deliver business value, right? That lets the customer make an order digitally, even if it has to be printed out on the other side and then plotted into another system, or you can use robots or something, right?" (CDO-3). CDOs also found that, by means of lightweight IT such as RPA, they could bypass heavyweight systems perceived as obstacles: "We have an insane amount of small and large processes where we could use an RPA for repetitive tasks. The ideal would certainly be full integration between systems, thereby avoiding those tasks. But we have many older systems that are hard to integrate, and that we'll have to live with. At some point, in an ideal world, you wouldn't need RPA technology, but that's not where we are" (CDO-8).

Shifting from the strong emphasis on digital lightweight technologies in 2016-2017, the story in the second round of interviews (2019-2020) turned toward the installed base and building a strong enterprise infrastructure. This shift seemed enabled by a more realistic perception of technology as an enabler, rather than the ultimate answer. One of the informants (CDO-21) elaborated on this realization: "There has been a lot of panic, and frequently you'll get the kind of "Why don't we have an app and stuff?" questions. There's constantly a new and updated panic situation, and the solution for those who do not really analyze the problem, that's technology. But the technology is an enabler, and you need to understand the problem before you say that an app is the answer, you know - what value does it actually provide to users?"

Some CDOs who had envisioned at an early stage exploiting promising new lightweight technologies realized that many of these were mostly hype: "In 2018, you were supposed to go for blockchain projects, and in 2020, that is all stone dead, and something else seems essential" (CDO-23) or a blind alley in their current context: "We had two pilots on chatbot, but we discovered that insurance is more complicated than banking, so we put the project on hold" (CDO-19).

The CDOs also realized that their firms over time have had too little overall control when new digital solutions were acquired, with the result that firms have untapped potential for exploiting existing systems more effectively. They now realized the need to refurbish their core systems, including technical infrastructures and architectures. Three topics emerged from these conversations. First, some CDOs realized that to move forward with digitalization, they needed to start by reducing the number of existing systems and reversing the effects from investments already made. For example, one organization reduced its current application portfolio by $50 \%$, from 160 to 80 .

Second, solving technical debt was high on the agenda at many organizations, as inefficiencies in the installed base were barriers to digital transformation. As CDO-21 noted: "We had - and still have - some very outdated technology that has shackled us, as the standard solutions we've been working with have been screwed to pieces over the 
years, and we have an enormous technical debt that hinders flexibility." Informants described the focus on the installed base as instrumental to realizing further ambitions. Their existing technological infrastructure was not robust enough for extensive digitalization, and they realized that considerable time and resources were needed to overhaul and rebuild the infrastructure. Informants talked at length about moving core systems to new platforms, harmonizing systems, and standardizing system use.

Third, the CDOs explained that they realized their organizations needed to draw up a new enterprise architecture: "Instead of asking ourselves what the customer wants, we now ask, 'What architecture do we need for this solution?", CDO-1 commented. The purpose, the informants explained, was to enable seamless integration and transparency between digital channels (web, desktop, and mobile), user interfaces, and services. To achieve this, a micro-service architecture with defined interfaces and APIs between the different systems was needed. Integration also moved beyond organizational borders, as the topic of digital ecosystems emerged. The CDOs explained that they now were focusing on working with other actors and firms in wider digital ecosystems. As CDO-19 explained: "We are now structuring our data so that they can be utilized across various sectors within our municipality. We asked the businesses in our municipality about what they really needed, and they responded that the most important initiative we could take was to build a digital platform in which we can share our data with them." Part of the focus on enterprise architecture involved working through business processes. Instead of implementing digital tools as a quick fix and focusing on automating individual business processes, e.g., with the help of robotic process automation (RPA), CDOs now saw the need for more long-term solutions. These included redesigning a comprehensive process architecture: "We started scaling down the use of RPAs - this low-hanging fruit has already been harvested. To harvest additional value, we first need to redesign our processes" (CDO-19). Informants emphasized the value of harmonizing processes and systems. Organizations that narrowed digitalization projects to front-office tools at an early stage had since found that this was not a fruitful limitation. As CDO-21 noted: "If you don't make new digital services and customer experiences in a way that is anchored in business processes, it's just...you might impress the customers for a short while, but then it's a lot like putting lipstick on a pig."

Overall, during the second phase, the CDOs put more emphasis on infrastructures and architectures, and explained that the prevailing - but increasingly informed - focus on digital transformation among executives had given the organizations more resources to address these complex tasks.

\subsection{Methodological shift}

The third shift we identified was a shift in the methodological approach to digitalization. During the first round of interviews, informants described a strong sense of urgency, and that quick progression and constantly launching new projects seemed mandatory. This sense of action as an imperative sometimes led to projects merely 'for the sake of the project itself' and sometimes unmanageable numbers of projects, as CDO-9 described:

"In total, we run more than 100 parallel projects at any time. On average, we start and complete, I think, about 15-20 projects each month. That is, of course, a very challenging balance. There are a lot of projects in which the pressure is high, I mean, there is a business case, a business area that really wants this project and wishes to start ASAP."

The sense of urgency affected their methodological approach, particularly during the front end of projects. CDOs described that whereas previously, a pre-project involving thorough analyses had been standard, projects now sought simpler and more speedy, informal approaches, going straight to the development of a basic solution - "simple prototypes which might involve kind of, well, paper clips behind the scene" (CDO-5). The CDOs described a culture in which risks were viewed as unavoidable to avoid losing the digital war. For many, it was almost a greater risk "not doing anything, just standing still" (CDO-10). The mantra at that point seemed: "Work fast and dare to fail." Simultaneously, the limited understanding of digital technology and what digital transformation entails hampered projects. And customer centricity as a mantra was not necessarily followed in practice: "Our strategy is focused on customers, but in practice, we are too focused on internal needs. The major shift is to turn the organization from thinking internal needs to actually placing the needs of the customers at the center, and let that guide much of our development, our priorities, and the paths we choose" (CDO-13).

During the second round, the CDOs described a gradual realization that more methodical approaches to digitalization were needed. One issue was to increase synergy between projects and efficiency in system development. Instead of the radical, fail-fast approach, a systematic, incremental approach was emerging. Innovation and experimentation were still important, but anchored in more systematic methods aiming for both speed and thoroughness, as CDO-23 described it: "I think the long-term perspective has to be that speed is important, but not speed at the expense of focus and the right level of diligence. Too much speed and random movements, rather than a clear direction, will cost you your momentum." The CDOs realized that managing too many projects simultaneously, some of which never were completed, hampered speed and productivity, 
particularly because key personnel and resources were scarce. Furthermore, the CDOs no longer perceived an opposition between systematic methods and innovation, but rather viewed the methods as an important enabler. As CDO-21 noted: "All these digital evangelists have talked about fail fast, but if you just fail fast, then there is no money in it. You need a methodology that lays the foundation that gives you the flexibility to experiment and fail and succeed fast." One reason for this realization seemed to be increased digital maturity in the organization, as CDO-7 noted: "We now set completely different requirements for capability in the organization. We expect that there is a completely different maturity out there, and we have checklists where we grade projects to find out if we are going to invest in the project or not."

The emerging approach included three central elements. First, CDOs emphasized training their organizations in specifying demands following structured methods and templates. Structured methods employed across projects allowed organizational actors to participate in discussions and specifications of solutions to a different extent than before, and to ensure comprehensive and wellthought-out solutions. Second, CDOs had come to recognize that big changes start small: "The smaller the change is, the better," CDO-22 noted. Informants told how they now sought to work incrementally, often combined with agile approaches and in structures such as agile teams. CDOs described benefits from the incremental and agile approach related to more effective IT development, establishment of local competence, interdisciplinary collaboration, and increased room for innovation. Third, rather than working on individual projects, CDOs now see the necessity of focusing on the bigger picture in terms of the entire customer journey, value chain, or product, as CDO3 stated: "The first three years, I kept screaming, 'There's a fire - hurry, hurry,' a line well known among us CDOs. But during the past year, I started putting the brakes on. We see that we cannot develop solutions while looking only at a small part of the value chain."

Customer centricity grounded in methods for mapping customer journeys and considering customer demands in a context meant that the customer was no longer just a slogan, as CDO-21 explained: "Customer centricity was sort of established as a concept, printed on posters on the wall in our head office, but hanging posters on the wall is a far cry from actually listening to the customers." Increasingly, CDOs started applying frameworks and methodologies, such as mapping the customer journey, service design, and business model canvas, and seeking to make business units adopt a wider perspective and view opportunities throughout the customer journey:
"We have a project that started with a facility requesting a new cash register system, or at least they needed one because they were required to report numbers a bit differently. But then we said, 'OK, but wouldn't it be beneficial to enable digital ticket sales?' 'Yes, we guess that would be good.' 'And then maybe it would be nice to not actually have to pick up the ticket, but just use a mobile phone and walk straight in?' 'Yes, probably'. So, you start at one end and then work together" (CDO-7).

An important means for shifting attention from initiating projects toward product-thinking was establishing permanent, stable teams working according to the DevOp methodology. These teams were given the responsibility for the whole life cycle of the firms' products or services, from development, via testing, to operation and maintenance.

\section{Discussion and conclusion}

In this paper, we set out to understand how chief digital officers' strategies evolve during the digital transformation. Using the lightweight and heavyweight IT framework as an analytical lens enabled a deeper understanding of how CDOs handle strategic, technological, and methodological aspects of the digital transformation, as an interplay between lightweight and heavyweight IT. Our analysis revealed major shifts over time in how CDOs perceive and approach the digital transformation. Typically, executives brought the $\mathrm{CDO}$ into the organization as a propagator of lightweight IT to propel the digital transformation. Our findings indicate that CDOs' evolving perception and strategies entailed that the role developed differently than the executives might have envisioned. As the CDOs' perception of digital transformation turned from a sense of emergency toward realism and a more long-term perspective, they realized that for the organization to take ownership of the digital transformation, increased digital maturity and stronger collaboration between business units and the IT department were essential. Also, CDOs' initial focus on lightweight, frequently hyped technologies gradually shifted toward a stronger emphasis on existing heavyweight systems and on lightweight-heavyweight integration. Methodologically, CDOs went from promoting experimental "paperclip methods" involving a rather high degree of risk, to realizing that innovation should be grounded in small steps with continuous improvement and more standardized methods, while considering the entire product, customer journey, or value chain.

To enable digital innovation, Bygstad [8] suggested that lightweight and heavyweight IT should not be integrated tightly, but remain separate entities loosely coupled in terms of technology, standards, and organization. Similarly, Tumbas et al. 
[22] found that decoupling digital and IT logics was a strategy that CDOs frequently employed in digital innovation projects. Such approaches to managing seemingly opposing elements might be described as "splitting" [30] them spatially or temporally. However, researchers have proposed that over time, such strategies might prove counterproductive, as they can lead to one element dominating the other, making a necessary balance difficult to achieve [31]. Moreover, research has demonstrated that managing oppositions is an ongoing, iterative, and dynamic process that might require combining and switching between different strategies [32]. Our research indicates that whereas autonomous digital innovation projects might benefit from a loose coupling between lightweight and heavyweight IT, a digital transformation accomplished over years requires a balance and systematic integration between these two knowledge regimes.

Our study provides an important contribution to research on digital transformation and the CDO's role. Much of the literature on digital transformation focuses on lightweight IT [9] and describes digital transformation in terms of disruption, radical change, and new value propositions [7, 33]. We contribute to research on chief digital officers by focusing on an aspect of CDOs' role, i.e., how their perceptions and strategies change over time, which had been studied scarcely in the literature. Moreover, most extant studies on CDOs' role dated from the early stages of the digital transformation and primarily employed cross-sectional case studies. However, our study examined how the role develops over time, in tune with evolving digital transformations within organizations.

We also contribute to the theory of lightweight vs. heavyweight IT. Whereas the theory originally was developed within the digital innovation field, we extended it to the context of digital transformation under the assumption that a digital transformation differentiates from a single digital innovation process on important aspects. Our findings demonstrate the necessity of balance and integration between lightweight and heavyweight IT as technologies and knowledge regimes, as well as support a perspective on digital transformation as not necessarily requiring a disruption of the existing value proposition, but rather continuous improvement and adaptation through smaller steps [34], while solidifying the entire enterprise architecture [26]. With this perspective, this study showcases the CDO's central role as an integrator of seemingly opposing elements of lightweight and heavyweight IT.

For practice, our study has several implications. A balance and integration between lightweight and heavyweight IT must imply that organizational ownership of the digital transformation should be distributed within the organization, relying on a solid understanding of customers and business needs, combined with technological competence and insight into security and privacy issues. As for technology, our findings demonstrate that a digital transformation should not be restricted to developing lightweight solutions, but also should entail exploiting existing heavyweight systems and building a firm foundation for new flexible solutions through core systems and integrations between front- and back-end systems. Furthermore, organizations must find methods to explore and exploit digital technologies that enable both flexibility and stability [23]. These are important insights for executives (including CDOs and CIOs) who seek to succeed with a digital transformation.

Also, despite the role's importance, as recent studies have indicated $[16,17,18]$, and the increasing number of organizations appointing CDOs over the past few years, academic empirical research on CDOs' contributions remains limited. Gaining value from establishing a CDO requires that executives have the right perspective on this role. A more thorough understanding of the role is important for organizations to define the position properly and, thus, truly benefit from its existence. For the CDOs themselves, our findings emphasize the need to move quickly beyond the hype and focus on balancing and integrating social and technical aspects of lightweight and heavyweight IT. This study enlightens CDOs on how to accomplish this.

This study has some limitations. It was conducted in a Norwegian context, limiting its generalizability. Furthermore, we examined CDOs' evolving strategies solely through their own perspectives. Future research might examine the topic in different contexts and might include other organizational actors' perspectives.

\section{References}

[1] S. Kunisch, M. Menz, and R. Langan, "Chief Digital Officers: An Exploratory Analysis of Their Emergence, Nature, and Determinants," Long Range Planning, 2020, 101999.

[2] S. Firk, A. Hanelt, J. Oehmichen, and M. Wolff, "Chief Digital Officers: An Analysis of the Presence of a Centralized Digital Transformation Role," Journal of Management Studies, 2021.

[3] I. Haffke, B.J. Kalgovas, and A. Benlian, "The Role of the $\mathrm{CIO}$ and the $\mathrm{CDO}$ in an Organization's Digital Transformation." Paper presented at the 37th International Conference on Information Systems, Dublin, Ireland, 2016.

[4] R.W. Gregory, M. Keil, J. Muntermann, and M. Mähring, "Paradoxes and the Nature of Ambidexterity in IT Transformation Programs," Information Systems Research, 2015, pp. 57-80.

[5] J. Peppard, "Rethinking the Concept of the IS Organization," Information Systems Journal, 2018, pp. 76-103.

[6] S. Tumbas, N. Berente, and J. vom Brocke, "Three Types of Chief Digital Officers and the Reasons 
Organizations Adopt the Role,” MIS Quarterly Executive, 2017.

[7] L.K. Wessel, A. Baiyere, R. Ologeanu-Taddei, J. Cha, and T.B. Jensen, "Unpacking the Difference Between Digital Transformation and IT-Enabled Organizational Transformation," Journal of the Association for Information Systems, 2020, pp. 102-129.

[8] B. Bygstad, "Generative Innovation: A Comparison of Lightweight and Heavyweight IT," Journal of Information Technology, 2017, pp. 180-93.

[9] G. Vial, "Understanding Digital Transformation: A Review and a Research Agenda," Journal of Strategic Information Systems, 2019, pp. 118-144.

[10] B. Bygstad and E. Øvrelid, "Architectural Alignment of Process Innovation and Digital Infrastructure in a HighTech Hospital," European Journal of Information Systems, 2020, pp. 220-237.

[11] J. Iden and B. Bygstad, "Managing Digital Transformation with Sociotechnical Micro-Foundations: A Dynamic Capabilities Approach," In Proceedings of the 54th Hawaii International Conference on System Sciences, 2021, p. 6462.

[12] S. Nambisan, K. Lyytinen, and Y. Yoo, "Digital Innovation: Toward a Transdisciplinary Perspective," In Handbook of Digital Innovation, Edward Elgar Publishing. 2020.

[13] K.S.R. Warner and M. Wäger, "Building Dynamic Capabilities for Digital Transformation: An Ongoing Process of Strategic Renewal," Long Range Planning, 2019, pp. 326-49.

[14] J. Butschan, S. Heidenreich, B. Weber, and T. Kraemer, "Tackling Hurdles to Digital Transformation the Role of Competencies for Successful Industrial Internet of Things (IIoT) Implementation," International Journal of Innovation Management, 2018, pp. 1-34.

[15] G.C. Kane, D. Palmer, A.N. Phillips, D. Kiron, and N. Buckley, "Achieving Digital Maturity: Adapting Your Company to a Changing World," MIT Sloan Management Review, 2017, pp. 1-31.

[16] S. Firk, A. Hanelt, J. Oehmichen, and M. Wolff, "Digital in the C-Suite: Antecedences and Performance Effects of Chief Digital Officer Appointments," Paper presented at the Academy of Management Annual Meeting, Boston, Massachusetts, 2019.

[17] K. Drechsler, H-T. Wagner, and V. Reibenspiess, "Risk and Return of Chief Digital Officers' AppointmentAn Event Study," Paper presented at the 40th International Conference on Information Systems, Munich, 2019.

[18] X, Zhan, Y. Mu, R. Nishant, and V.R. Singhal, "When Do Appointments of Chief Digital or Data Officers (CDOs) Affect Stock Prices?" IEEE Transactions on Engineering Management, 2020, pp. 1-14.

[19] A. Singh and T. Hess, "How Chief Digital Officers Promote the Digital Transformation of Their Companies," MIS Quarterly Executive, 2017, pp. 1-17.

[20] F. Reck and A. Fliaster, "Four Profiles of Successful Digital Executives," MIT Sloan Management Review, 2019, pp. 1-7.

[21] A. Singh, P. Klarner and T. Hess, "How Do Chief Digital Officers Pursue Digital Transformation Activities? The Role of Organization Design Parameters," Long Range Planning, 2020, p. 101890.

[22] S. Tumbas, N. Berente, and J.V. Brocke, "Digital Innovation and Institutional Entrepreneurship: Chief Digital Officer Perspectives of Their Emerging
Role," Journal of Information Technology, 2018, pp. 188202

[23] R. Sun and M. Zhang, "Demystifying the Paradox of Stability and Flexibility in Information Systems Design: An Affordance Perspective," In Proceedings of the 39th International Conference on Information Systems, 2018, $1-15$.

[24] S. Berghaus and A. Back, "Stages in Digital Business Transformation: Results of an Empirical Maturity Study," In the 10th Mediterranean Conference on Information Systems, Paphos, Cyprus, 2016.

[25] M. Fitzgerald, N. Kruschwitz, D. Bonnet, and M. Welch, "Embracing Digital Technology: A New Strategic Imperative," MIT Sloan Management Review, 2014.

[26] Y. Gong, J. Yang, and X. Shi, "Toward a Comprehensive Understanding of Digital Transformation in Government: Analysis of Flexibility and Enterprise Architecture," Government Information Quarterly, 2020, 101487.

[27] S. Mithas, A. Tafti, and W. Mitchell, "How a Firm's Competitive Environment and Digital Strategic Posture Influence Digital Business Strategy," MIS Quarterly, 2013, pp. 511-536.

[28] DESI, "The Digital Economy and Society Index 2020 - Norway," European Commission, 2020.

[29] OECD, "OECD Economic Surveys: Norway 2019," Organization for Economic Cooperation and Development, 2019.

[30] W.K. Smith and M.W. Lewis, "Toward a Theory of Paradox: A Dynamic Equilibrium Model of Organizing," Academy of Management Review, 2011, pp. 381-403.

[31] M. Seo, L.L. Putnam, and J.M Bartunek, "Dualities and Tensions of Planned Organizational Change," Handbook of Organizational Change and Innovation, Oxford University Press, Oxford, UK, 2004.

[32] C. Abdallah, J-L.Denis, and A.Langley, "Having Your Cake and Eating It Too: Discourses of Transcendence and Their Role in Organizational Change Dynamics," Journal of Organizational Change Management, 2011, pp. 333-348.

[33] J. Karimi and Z. Walter, "The Role of Dynamic Capabilities in Responding to Digital Disruption: A Factor-Based Study of the Newspaper Industry," Journal of Management Information Systems, 2015, pp. 39-81.

[34] N. Furr and A. Shipilov, “Digital Doesn't Have to Be Disruptive: The Best Results Can Come From Adaptation Rather Than Reinvention," Harvard Business Review, 2019, pp. 94-104. 